Infusionstherapie 1990;17:287

\title{
Impressum, Vol. 17, No. 6, 1990
}

Band 17, Heft 6, Dezember 1990

Infusionstherapie

Internationale Zeitschrift für Infusionstherapie, klinische Emährung und Transfusionsmedizin

Herausgeber

S. Karger

Verlag für Medizin und Naturwissenschaften GmbH,

Postfach 1724, D-8034 Germering

Presserechtlich verantwortlich: Walter Kunz, Gesellschafter

DAKI

O

Offizielles Organ

der Deutschen Arbejtsgemeinschaft

für künstliche Ernährung (DAKE)

AKE

Offizielles Organ

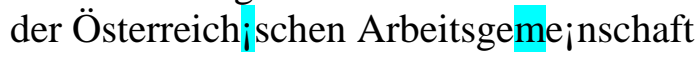

für klinische Ernährung (AKE)

Offizielles Organ der Deutschen Gesellschaft für Transfusionsmedizin und Immunhämatologie

Gründungsherausgeber

H. Reissigl, w. Hofrat, Innsbruck

Schriftleitung

K.H. Bäßler, Mainz; A. Grünert, Ulm: V. Kretschmer, Marburg: K. Widhalm, Wien G. Wolfram, München

Wissenschaftlicher Beirat

M. Adolph, Augsburg:

F.W. Ahnefeld, Ulm;

K.H. Bäßler, Mainz;

W. Behrendt, Aachen;

H. Bergmann, Linz;

C. Bode, Köln;

P. Deetjen, Innsbruck;

W. Dick, Mainz;

R. Dölp, Fulda;

H. von Domarus, Lübeck;

W. Druml, Wien;

J. Eckart, Augsburg;

P. Ferenci, Wien:

H. Förster, Frankfurt;

R. Glaser von Roman, Düsseldorf; 
A. Grünert, Ulm;

J.M. Hackl, Innsbruck;

W. Haider, Wien;

M. Halmágyi, Mainz: W. Hartig, Leipzig; O. Heidenreich, Aachen: U. Henneberg, Berlin;

E. Holm, Mannheim;

G. Kleinberger, Steyr;

K.F. Kopp, München;

V. Kretschmer, Marburg; J. Kult, Bad Mergentheim; H.G. Lasch, Gießen; H. Lochs, Wien; D.

Löhlein, Dortmund; H. Mehnert. München; J.M. Müller, Köln; K. Peter, München;

F. Pohlandt, Ulm;

U. Rabast, Hattingen; H. Reissigl, Innsbruck;

P. Riederer, Würzburg; H. Rossegger, Graz;

E. Roth, Wien;

P. Schauder, Göttingen;

H.P. Schuster, Hildesheim;

M. Semsroth, Wien;

K. Steinbereithner, Wien;

H.J. Steinhardt, Mainz;

H. Stoeckel, Bonn;

B. Szczygiel, Warschau;

W. Vahlensieck, Bonn;

R. Weiner, Leipzig;

R. Wenger, Wien;

K. Widhalm, Wien;

F. Willig, Heidelberg;

G. Wolfram, München;

R. Zander. Mainz

Erscheinungsweise

Die Zeitschrift erscheint zweimonatlich; pro Jahr erscheint 1 Band zu je 6 Heften. Abonnementpreis

Bezugspreis für Jahrgang 17, 1990, DM 148,- I öS 1036,- I SFr 116,-. 1 Einzelheft kostet DM 28,- I öS 196,- I SFr 22,-, einschließlich MwSt., zuzüglich Postgebühren.

Der Abonnementpreis ist im voraus zahlbar. Das Abonnement der Zeitschrift läuft weiter, wenn es nicht spätestens 4 Wochen vor Abschluß eines Bandes abbestellt wird.

Abonnementbestellungen können bei jeder Buchhandlung oder direkt beim Verlag aufgegeben werden:

Bundesrepublik Deutschlandl'Österreich: S. Karger GmbH, Postfach 1724, D-8034

Germering/München, Telefon: (089) 843035, Telex: 524865 D, Telefax: 8418083, Postgiro:

München 40080-807 Schweiz: S. Karger AG, Allschwilerstr. 10, Postfach, CH-4009 Basel, Tel.: (061) 3061111, Telex 62652 CH, Telefax (061) 3061234. Manuskripte

Diese sind direkt an den Verlag zu senden: wegen Einzelheiten siehe unter «Hinweise für Autoren» in diesem Heft. Anzeigen

S. Karger Verlag für Medizin und Naturwissenschaften GmbH, Postfach 1724, D-8034

Germering, Telefon (089) 843035. Gül·tig ist die Preisliste Nr. 8 vom 1.10.1986. 
Für den Inhalt außerhalb des redaktionellen Teiles (insbesondere Anzeigen, Industrieinformationen, Pressezitate und Kongreßinforma-tionen usw.) übernehmen Schriftleitung, Beirat und Verlag keine Gewähr.

Eine Markenbezeichnung kann warenzeichenrechtlich geschützt sein, auch wenn bei ihrer Verwendung in dieser Zeitschrift das Zeichen ${ }^{\circledR}$ oder ein anderer Hinweis auf etwa bestehende Schutzrechte fehlen sollte. Für Satzfehler, insbesondere bei Dosierungsangaben. wird keine Gewähr übernommen.

Alle Rechte, insbesondere das Recht der Vervielfältigung und Mikro-kopie sowie der Übersetzung, vorbehalten. Nachdruck, auch auszugs-weise, nur mit Genehmigung des Verlages. Fotokopien dürfen nur für den persönlichen Gebrauch als Einzelkopien hergestellt werden. Jede im Bereich eines gewerblichen Unternehmens zulässig hergestellte oder benutzte Kopie dient gewerblichen Zwecken gem. § 54(2) UrhG und verpflichtet zur Gebührenzahlung an die Verwertungsgesellschaft WORT, Abt. VG Wissenschaft, Goethestraße 49, D-8000 München 2. (C) Copyright 1990 by S. Karger, Verlag für Medizin und Naturwissenschaften GmbH, Postfach 1724, D-8034 Germering (BRD)

Satz und Druck: Walter Biering GmbH, Grafischer Betrieb, Freisinger Landstraße 21, D-8000 München 45 (BRD)

KARGER 